\title{
QUEEN'S
UNIVERSITY
BELFAST
}

\section{Pre-radiotherapy dental extractions in patients with head and neck cancer: a Delphi study.}

Moore, C., McLister, C., O'Neill, C., Donnelly, M., \& McKenna, G. (2020). Pre-radiotherapy dental extractions in patients with head and neck cancer: a Delphi study. Journal of Dentistry.

https://doi.org/10.1016/j.jdent.2020.103350

Published in:

Journal of Dentistry

Document Version:

Peer reviewed version

Queen's University Belfast - Research Portal:

Link to publication record in Queen's University Belfast Research Portal

\section{Publisher rights}

Copyright 20_Elsevier.

This manuscript is distributed under a Creative Commons Attribution-NonCommercial-NoDerivs License

(https://creativecommons.org/licenses/by-nc-nd/4.0/), which permits distribution and reproduction for non-commercial purposes, provided the author and source are cited.

\section{General rights}

Copyright for the publications made accessible via the Queen's University Belfast Research Portal is retained by the author(s) and / or other copyright owners and it is a condition of accessing these publications that users recognise and abide by the legal requirements associated with these rights.

Take down policy

The Research Portal is Queen's institutional repository that provides access to Queen's research output. Every effort has been made to ensure that content in the Research Portal does not infringe any person's rights, or applicable UK laws. If you discover content in the Research Portal that you believe breaches copyright or violates any law, please contact openaccess@qub.ac.uk. 


\section{Abstract - Pre-radiotherapy dental extractions in patients with head and neck cancer: a Delphi study.}

\section{Objectives}

To gain a consensus from consultants in restorative dentistry about the types of teeth that should be extracted from head and neck cancer patients (HNC) pre-radiotherapy.

\section{Materials}

Literature- and clinician-informed questionnaires were emailed to an 'expert panel' of consultants $(n=24 / 28 ; 86 \%)$ in the United Kingdom (UK) and Ireland on three consecutive occasions (Delphi rounds). The results of Round 1 were used to revise the questionnaire that was distributed in Round 2, and this procedure was repeated for Round 3. During Rounds 2 and 3, participants were asked to indicate, on a 5-point Likert scale, their level of agreement with a series of statements on the types of teeth that should be extracted pre-radiotherapy. The target level of consensus for each statement was $70 \%$.

\section{Results}

In Round 2, there was consensus-agreement for 69 of 102 statements (i.e. $\geq 70 \%$ of participants rated 'agree' or 'strongly agree' to the relevant statement). Consensus agreement was also achieved for 20 of 28 statements in Round 3. Therefore, a total of 89 consensus statements are presented that illuminate the decision-making process for the pre-radiotherapy extraction of molar, premolar, and anterior teeth with periodontal pocketing, furcation disease, mobility, caries, tooth-wear, apical disease, or other pathology.

\section{Conclusion}

The statements represent the consensus professional views of participated consultants in restorative dentistry in the UK and Ireland regarding the types of teeth that should be extracted from HNC patients pre-radiotherapy. The results provide a platform for the development of future guidelines.

\section{Clinical Significance}

Pre-radiotherapy dental assessments for head and neck cancer patients are considered mandatory. This study presents different criteria that should be considered for the treatment planning of these patients in relation to pre-radiotherapy extractions, according to the collective consensus opinion of participated consultants in restorative dentistry in the UK and Ireland.

\section{Highlights}

- This Delphi study collated 'expert' opinion regarding pre-radiotherapy dental extractions.

- Consensus statements outline the types of teeth that should be extracted preradiotherapy.

- It is envisaged that the study's results will help to inform the development of new guidelines. 


\section{Keywords}

Head and neck neoplasms

Radiotherapy

Dental caries

Periodontal disease

Tooth extraction

Oral health

\section{Abbreviations}

BSSPD - British Society of Prosthodontics

HNC - head and neck cancer

IMRT - intensity modulated radiotherapy

$I Q R$ - interquartile range

$M$ - median

ORN -osteoradionecrosis

$P$ - percentage agreement

QoL - quality of life

QUB - Queen's University Belfast

$S$ - standard deviation

UK - United Kingdom

$X$ - mean

\section{Introduction}

Head and neck cancer (HNC) is the sixth most common malignancy worldwide.[1] Approximately 12,000 people are diagnosed with HNC in the United Kingdom (UK) every year, $[2,3]$ and between $42-84 \%$ of these patients are treated with radiotherapy depending on the location of the tumour[4]. Radiotherapy can be used as a singletreatment modality in predilection to surgery - particularly for base of tongue and laryngeal cancers, where preservation of functions such as swallowing and speech, are of paramount importance.[5] Alternatively, radiation therapy can be delivered postoperatively following resection of the tumour, or in combination with chemotherapy.[5]

Unfortunately, even with radiotherapy dose-fractionation, radiation treatment can damage normal tissues,[6] and this may result in adverse side-effects such as mucositis,[7] trismus,[8] salivary gland hypofunction,[9] dental caries,[10] periodontal disease,[11] and osteoradionecrosis[12]. The incidence of dental caries in postradiotherapy HNC patients has been estimated at 29\%,[13] and between $18-68 \%$ of HNC patients suffer from post-radiotherapy periodontitis[14-19].

HNC patients are primarily at increased risk of post-radiotherapy dental caries due to the indirect effects of radiation (e.g. hyposalivation), however, structural damage to the teeth, such as enhanced enamel porosity, may also be contributory.[20-22] Radiationinduced injury to the periodontal ligament, including decreased vascularity and acellularity, in combination with elevated plaque levels and altered oral flora (both associated with hyposalivation), also increase the risk of periodontitis.[20,23,24]

Post-radiotherapy dental caries and periodontal disease are leading causes of the need for tooth extractions in HNC patients.[25] Dental extractions performed in irradiated 
patients increase the risk of osteoradionecrosis (ORN).[12,26,27] ORN is a condition characterised by the exposure of non-healing, devitalised bone, and it can be associated with severe oro-facial pain and decreased quality of life (QoL).[26,28,29] The overall incidence of ORN following tooth extraction in post-radiotherapy HNC patients has been estimated at 7\%.[12]

To obviate the risk of post-radiotherapy dental disease, post-radiotherapy tooth extractions, and the concomitant risk of ORN, it is recommended that newly diagnosed HNC patients undergo thorough oral assessment and be rendered dentally fit prior to radiotherapy.[30] Patients should also be educated on the potential oral health risks of radiation treatment and instructed on effective oral hygiene practice, fluoride application, and dietary modification.[30]

Furthermore, teeth of doubtful prognosis should be extracted prior to radiotherapy.[30] Substantial variation exists, however, regarding clinical decision-making for exactions and the types of teeth that should be removed, particularly in the absence of international guidelines. For example, some clinicians advocate the removal of all teeth of "dubious prognosis" (e.g. those with deep caries, deep periodontal pockets, or nonvital teeth),[30] whilst other clinicians recommend retaining all potentially restorable teeth prior to radiotherapy[31,32]. The declining incidence of ORN, newer radiotherapy technologies with enhanced ability to spare tumour-surrounding normal tissue, and the potential for pre-radiotherapy extractions to also cause ORN, are cited in support of this latter view.[12,33,34]

Consequently, there is a need to clarify and improve professional decision-making in this particular clinical domain of patient-treatment. This study surveys and elicits professional opinion from consultants (clinical specialists) in restorative dentistry in the UK and Ireland regarding pre-radiotherapy dental extractions for HNC patients, in order to address this need for improved understanding, and to gain a consensus about the types of teeth that should be removed prior to radiotherapy.

\section{Materials and methods}

The study employed 'Delphi' methodology.[35] The Delphi technique is described as a structured group communication process that affords an opportunity for a group of 'experts' within a specific field to resolve differences of opinion over a series of information-sharing, iterative rounds, and attain a collective consensus that, in turn, may be used to guide future clinical decision-making.[35,36] The Delphi technique is considered a "flexible" research method that can be tailored to meet a study's specific objectives.[36] There is no standard statistical process for determining a sample size for a Delphi study, however, a target of 13 to 30 respondents has been recommended.[35,36]

Ethical approval for the study was granted by the Joint Research Ethics Committee, School of Medicine, Dentistry, and Biomedical Sciences, Queen's University Belfast (QUB).

An 'expert' panel of consultants in restorative dentistry was assembled using the following inclusion criteria - "any consultant in restorative dentistry working in the UK 
and/or the Republic of Ireland actively involved in the pre-radiotherapy dental treatment planning of patients with HNC."

Potential participants were invited to partake in the study via email invitation. Invitatory emails were sent to all members of the British Society of Prosthodontics (BSSPD) by the BSSPD, and to dental clinicians at Trinity College Dublin and University College Cork (the only dental hospitals in Ireland) by the Dean of Dental Science at Trinity College Dublin, and the Deputy Head of the College of Medicine \& Health at University College Cork, respectively. Recruitment took place over a period of four weeks. The target number of participants was 15 to 20 (in line with previous studies), $[35,37,38]$ however, all eligible candidates who were willing to take part were recruited. Participants completed a series of questionnaires over three separate, iterative rounds:

\section{Round 1}

The Round 1 questionnaire consisted of open- and close-ended questions divided into three sections (Supplementary Material 1). In Section A, each participant was asked to define the terms: 'good standard of oral hygiene', 'dentally neglectful', 'poor oncology prognosis', 'high radiation dose', and 'tooth of strategic importance'. Furthermore, participants were also asked to indicate what they felt should be the 'minimum dental extraction healing time pre-radiotherapy'.

In Section B, participants were asked to rate their level of agreement, on a 5-point Likert scale ('strongly agree' - 'strongly disagree'), with a series of statements sourced from a review of the literature and informed by the collective knowledge of the clinical members of the research team.[35] For example: "All grade II mobile teeth (or worse) should be extracted prior to radiotherapy?" A free-textbox was also provided the end of each question to afford participants an opportunity to add comments. The literature review was undertaken by two independent researchers using a predefined search strategy (Supplementary Material 2), adopting a systematic approach to screening and data collection.

In Section C, participants were asked to indicate the average number of preradiotherapy dental assessments per week that they undertook; whether intensitymodulated radiotherapy (IMRT) was available at their unit; and who most commonly performed pre-radiotherapy extractions at their unit.

A draft version of the Round 1 questionnaire was piloted with five consultants in restorative dentistry in the School of Dentistry, QUB, to determine its ease of use, clarity, and understanding.[35] Appropriate modifications were then made. These consultants were excluded from participating in the main study. The definitive Round 1 questionnaire was designed for completion using SurveyMonkey software, and an electronic link to facilitate its completion was then emailed to all participants.

\section{Round 2}

Following analysis of data from Round 1, a Round 2 questionnaire was developed (Supplementary Material 3) based on the responses to the previous round, and then emailed to participants who were asked to follow a similar procedure to Round 1 . The main difference was that in order to inform their decision making, participants' 
responses to each question/statement from the previous round (Round 1) were provided along with the Round 2 questionnaire. The overall group response to each question/statement from Round 1 was also presented in the form of a bar chart. In addition, a summary of the literature review was provided to participants as an appendix to the Round 2 questionnaire.

\section{Round 3}

A similar procedure was followed for the revision and completion of the questionnaire used in Round 3 (Supplementary Material 4). Participant's own responses, and the overall group response to each question from Round 2, were forwarded as an appendix to the Round 3 questionnaire. The overall group response to each question from Round 2 was summarised using the mean and median responses, the standard deviation and interquartile range, the relative frequency of each response, and whether or not each statement had attained group consensus (i.e. greater than or equal to $70 \%$ of participants responding 'strongly agree' or 'agree').

\section{Consensus agreement}

The target level of consensus agreement for each statement was set, a priori, at 70\%.[35,37] Statements that attained consensus during Round 2 were 'banked' and not included in Round 3.[35,36] Statements that did not attain consensus during Round 2 were modified based on the comments given and included in the Round 3 questionnaire.[39,40]

\section{Statistical analysis}

All quantitative data were analysed using IBM SPSS Statistics and qualitative data was content-analysed.[41] Similar statements were then collapsed into a single, mirroring statement.[41] The primary outcome of interest was the level of consensus agreement regarding each statement as indicated by the mean and median responses, standard deviation and interquartile range, and the percentage level of agreement.

\section{$\underline{\text { Results }}$}

A flow-diagram summarising the study's results is presented in Figure 1. 


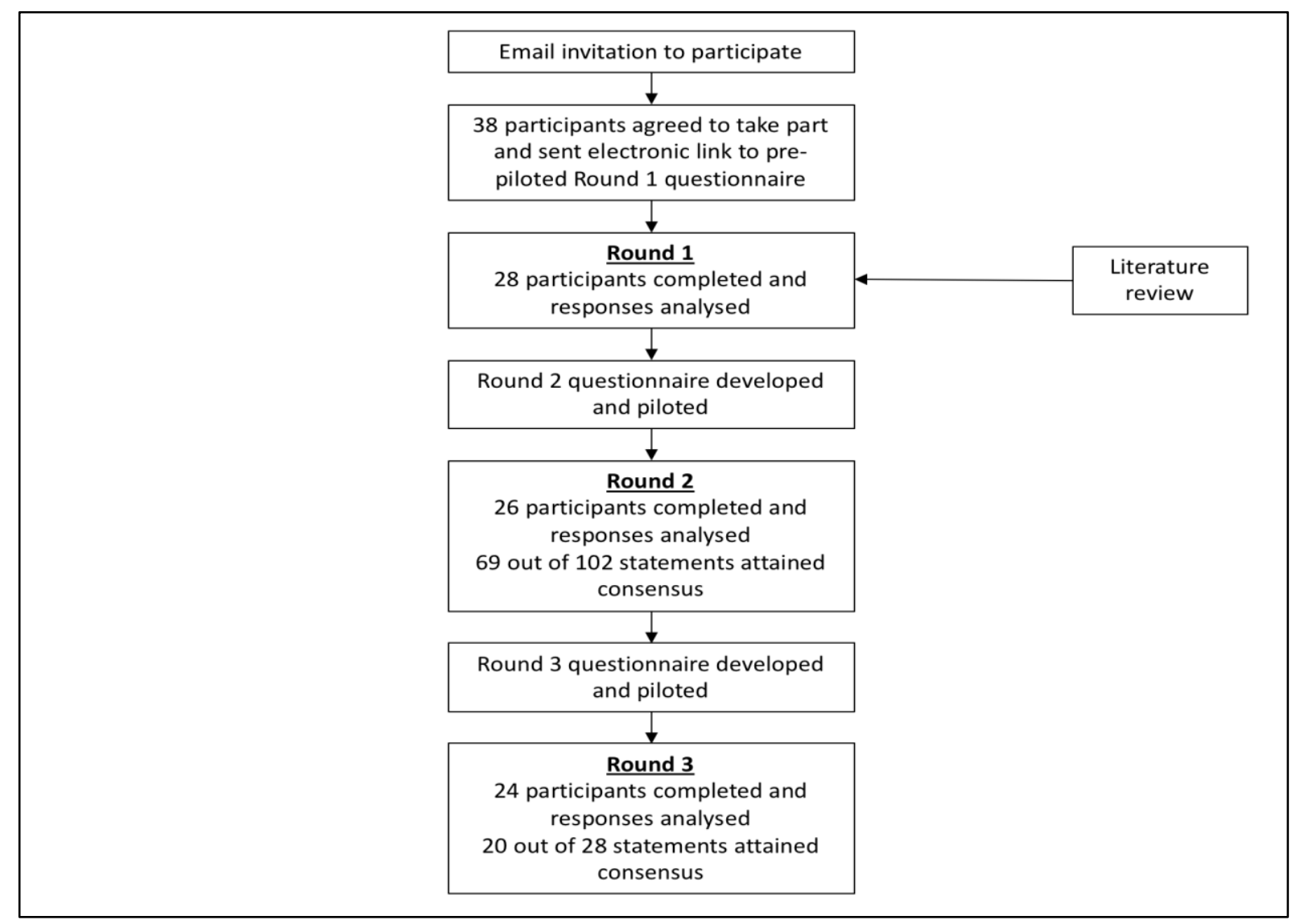

Figure 1: Flow diagram outlining the results of this Delphi study.

\section{Round 1}

A total of 38 eligible participants agreed to take part in the study after initial email invitation. Of the 38 participants who were sent the electronic link to the Round 1 questionnaire, 28 completed it in its entirety.

The results from Section A of the Round 1 questionnaire are outlined in Table 1. The shortest post-extraction healing time suggested was 7 days and was indicated by 4 (14\%) respondents. The longest post-extraction healing time suggested was 2 months and was proposed by $1(4 \%)$ respondent. The most common answers were 10 days (29\%) and 14 days (36\%).

A total of 21 (76\%) respondents from Round 1 considered a dose of greater than or equal to 50 Gray to be indicative of a 'high radiation dose'. This figure is corroborated by studies in the literature that have demonstrated that the occurrence of osteoradionecrosis (ORN) is exceedingly rare below a radiation dose of less than 50 Gray.[12,42-44]

'Parotid gland radiation sparing' is considered to be an average radiation dose of less than 25 Gray to the bilateral parotid glands, or an average radiation dose of less than 20 Gray to one of the parotid glands (as per the QUANTEC guidelines).[45]

A patient with a 'good standard of oral hygiene':

- $\quad$ Brushes their teeth twice daily

- Uses interdental cleaning aids 
- Attends their general dental practitioner on a regular basis

- Has no plaque visible on the facial surfaces of their anterior teeth

- Has no or minimal supra-gingival calculus

- Has a plaque score of less than $20 \%$

- Has no active caries

- Has no active periodontal pocketing

A patient deemed to be 'dentally neglectful':

- Has a poor standard of oral hygiene (i.e. does not meet the above criteria)

- Has multiple grade II or grade III mobile teeth throughout their mouth

- Is likely to be partially dentate

- Has a very high caries rate (has three or more actively carious teeth)

- Has multiple failing restorations

- Has uncontrolled active periodontitis

- Has multiple retained roots

- Has gross toothwear

- Has large deposits of calculus throughout their mouth

- Is not registered with a general dental practitioner, or is an irregular attender

- Has a poor attitude or poor motivation regarding their dental care and/or their diet

Liaison with a patient's clinical oncologist is vital before considering whether or not a patient has a 'poor oncology prognosis', however, indicative factors may include:

- $\quad$ A large tumour ( $\geq \mathrm{T} 4$ on TMN classification)

- $\quad$ Extra-capsular nodal spread

- $\quad$ Distant metastases

- $\quad$ Skull base/brain involvement

- $\quad$ A p16 negative tumour

- $\quad$ The patient is to receive palliative treatment only

- $\quad$ The patient has multiple co-morbidities and continues to smoke and consume alcohol

A 'tooth of strategic importance' may be:

- $\quad$ A denture abutment to prevent a 'free-end saddle'.

- $\quad$ An appropriate bridge abutment

- $\quad$ A tooth required to retain and support a maxillary or mandibular obturator

- $\quad$ Maxillary and mandibular canines or first permanent molars

- $\quad$ A tooth of aesthetic importance

- $\quad$ A tooth responsible for maintaining a shortened dental arch

Table 1: Summary of the results from Section A of the Round 1 questionnaire.

In Section B, a total of 4 statements attained consensus agreement (i.e. $\geq 70 \%$ of respondents rating 'agree' or 'strongly agree') - statement (f), statement (k), statement $(\mathrm{t})$, and statement $(\mathrm{u})$. However, in all 4 instances, respondents overwhelmingly indicated that the precise wording of each statement should be modified based on other criteria (e.g. a patient's attitude to oral hygiene practice, or the radiation dose exposure of the teeth) before they could fully agree to it. Consequently, these statements were not 'banked' and changed accordingly, before re-inclusion in Round 2. 
The results from Section $\mathrm{C}$ are summarised in Table 2. The majority of participants (76\%) dentally assessed one to five pre-radiotherapy HNC patients at their unit every week. Furthermore, most (94\%) respondents had intensity modulated radiation therapy (IMRT) available at their unit, and just over two-thirds (68\%) of preradiotherapy dental extractions were being performed in a hospital oral surgery setting.

\begin{tabular}{|c|c|c|c|c|}
\hline \multicolumn{5}{|c|}{ Round 1 - Section C } \\
\hline $\begin{array}{l}\text { Average number of } \\
\text { pre-radiotherapy HNC } \\
\text { patients assessed per } \\
\text { week? }\end{array}$ & $1-5$ & $6-10$ & 11-15 & $16-20$ \\
\hline $\begin{array}{l}\text { Percentage of } \\
\text { respondents (\%) }\end{array}$ & 76 & 21 & 0 & 3 \\
\hline $\begin{array}{l}\text { IMRT available at } \\
\text { respondent's unit? }\end{array}$ & Yes & No & Don't know & \\
\hline $\begin{array}{l}\text { Percentage of } \\
\text { respondents }(\%)\end{array}$ & 94 & 3 & 3 & \\
\hline $\begin{array}{l}\text { Who most commonly } \\
\text { undertakes pre- } \\
\text { radiotherapy dental } \\
\text { extractions? }\end{array}$ & $\begin{array}{c}\text { Hospital } \\
\text { oral } \\
\text { surgeon (or } \\
\text { member of } \\
\text { their team) }\end{array}$ & $\begin{array}{c}\text { Hospital } \\
\text { restorative } \\
\text { dentist (or } \\
\text { member of } \\
\text { their } \\
\text { team) }\end{array}$ & $\begin{array}{l}\text { Community } \\
\text { dental } \\
\text { officer }\end{array}$ & $\begin{array}{c}\text { General } \\
\text { dental } \\
\text { practitioner }\end{array}$ \\
\hline $\begin{array}{l}\text { Percentage of } \\
\text { respondents }(\%)\end{array}$ & 68 & 20 & 8 & 4 \\
\hline
\end{tabular}

Table 2: Summary of the results from Section C of the Round 1 questionnaire.

\section{Round 2 and Round 3}

A total of 26 participants completed Round 2 (drop-out of 2 participants from Round 1 ) and 24 participants completed Round 3 (drop-out of 2 participants from Round 2). Consensus agreement was attained for 69 out of 102 statements in Round 2, and for 20 out of 28 statements in Round 3 (see Tables 3 and 4 below). The results are presented as two separate pools of statements - statements that achieved consensus agreement (Pool 1) and statements that did not achieve consensus agreement (Pool 2). The mean $(X)$ and median $(M)$ responses to each of the statements in Pools One and Two are presented, together with the standard deviation $(S)$, the interquartile range $(I Q R)$, and the percentage level of agreement $(P-\%)$ for each statement. $(1=$ 'strongly disagree', $2=$ 'disagree', $3=$ 'neutral', 4= 'agree', 5= 'strongly agree') 


\section{Pool ONE - Consensus statements}

\section{Patients deemed to have a 'poor oncology prognosis'}

Pre-radiotherapy extractions in patients deemed to have a 'poor oncology prognosis' may be limited to:

- grade III mobile teeth $(X=4.12, M=4, S=0.71, I Q R=1, P=81 \%)$

- $\quad$ symptomatic teeth/those with acute infection ( $X=4.52, M=5, S=0.50, I Q R=1, P=100 \%)$

- teeth likely to become symptomatic (e.g. unrestorable carious cavity, obvious apical pathology not amenable to root-canal treatment) ( $X=4.35, M=4, S=0.48$, $I Q R=1, P=100 \%)$

\section{Mobile teeth}

1. Teeth that are grade III mobile should be extracted prior to radiotherapy $(X=4.38$, $M=4.5, S=0.88, I Q R=1, P=96 \%)$

2. Teeth that are grade II mobile and are to be exposed to $\geq 50$ Gray should be extracted prior to radiotherapy $(X=4.00, M=4, S=0.95, I Q R=1.5, P=74 \%)$

3 . Teeth that are grade II mobile, are periodontally stable (i.e. have no periodontal pockets), and are to be exposed to $<50$ Gray may be retained prior to radiotherapy ( $X=$ 3.63, $M=4, S=0.77, I Q R=1, P=71 \%$ )

4. Teeth that are grade II mobile, are deemed to be of strategic importance, and are to be exposed to $<50$ Gray may be retained prior to radiotherapy $(X=3.82, M=4, S=0.82$, $I Q R=0, P=83 \%$ )

\section{Periodontal pocketing}

Teeth that have a periodontal pocket of greater than $5 \mathrm{~mm}$ (i.e. $\geq 6 \mathrm{~mm}$ ) should be extracted prior to radiotherapy when:

- the tooth is grade II or III mobile and is to be exposed to $\geq 50$ Gray ( $X=4.38, M=4$, $S=0.65, I Q R=1, P=92 \%)$

- the patient is considered to be dentally neglectful and the tooth is to be exposed to $\geq 50$ Gray ( $X=4.31, M=4, S=0.61, I Q R=1, P=92 \%$ )

- the tooth has severe clinical attachment loss/marginal bone loss and is to be exposed to $\geq 50$ Gray ( $X=4.31, M=4, S=0.72, I Q R=1, P=92 \%$ )

- the tooth has a $\geq 8 \mathrm{~mm}$ pocket and is to be exposed to $\geq 50$ Gray $(X=4.50, M=4.5$, $S=0.75, I Q R=1, P=92 \%)$

\section{Furcation disease}

Teeth with furcation disease should be extracted prior to radiotherapy when:

- the tooth is grade II or III mobile ( $X=3.84, M=4, S=1.01, I Q R=0, P=76 \%)$

- the tooth has a grade III furcation defect and is to be exposed to $\geq 50$ Gray ( $X=$ 4.13, $M=4.5, S=1.03, I Q R=2, P=71 \%$ )

- the tooth has a periodontal pocket of greater than $5 \mathrm{~mm}$ (i.e. $\geq 6 \mathrm{~mm}$ ) and is to be exposed to $\geq 50$ Gray ( $X=4.42, M=4.5, S=0.65, I Q R=1, P=92 \%$ )

- the tooth is non-functional, is NOT considered to be a strategic tooth, and is to be exposed to $\geq 50$ Gray $(X=4.19, M=4, S=0.83, I Q R=1, P=88 \%)$

- the patient is considered to be dentally neglectful and the tooth is to be exposed to $\geq 50$ Gray ( $X=4.31, M=4, S=0.54, I Q R=1, P=96 \%$ )

- the tooth has severe clinical attachment loss/marginal bone loss and is to be exposed to $\geq 50$ Gray ( $X=4.31, M=4, S=0.72, I Q R=1, P=92 \%$ ) 


\section{Tooth-restoration margin}

Teeth requiring restoration that have a tooth-restoration margin that extends greater than $1 \mathrm{~mm}$ subgingivally should be extracted prior to radiotherapy when:

- the tooth is NOT amenable to restoration ( $X=3.83, M=4, S=0.99, I Q R=0.5, P=75 \%)$

- the patient is considered to be dentally neglectful and the tooth is to be exposed to $\geq 50$ Gray ( $X=4.08, M=4, S=0.63, I Q R=0, P=84 \%$ )

- the tooth is a premolar or molar, is NOT considered to be of strategic importance, and is to be exposed to $\geq 50$ Gray ( $X=3.79, M=4, S=0.88, I Q R=0.25, P=75 \%$ )

\section{Root caries}

Teeth with active root caries affecting two or more surfaces should be extracted prior to radiotherapy when the tooth is to be exposed to $\geq 50$ Gray* $(X=3.83, M=4, S=0.96, I Q R=0$, $P=79 \%)$

*(Teeth with active root caries affecting two or more surfaces should be extracted prior to radiotherapy when the tooth is to be exposed to $\geq 50$ Gray and there will be NO parotid gland sparing $(X=4.04, M=4, S=1.07, I Q R=1, P=82 \%))$

\section{Other pathology}

Teeth with root-perforations, or root-resorption, or root-fractures, or retained instruments, that have associated pathology (e.g. apical disease or gross periodontal pocketing), should be extracted prior to radiotherapy when the tooth is to be exposed to $\geq 50$ Gray ( $X=4.75, M=5, S=0.44, I Q R=0.25, P=100 \%$ )

\section{Molar teeth}

1. Molar teeth affected by caries or toothwear with suspected pulpal involvement should be extracted prior to radiotherapy when:

- the molar is NOT amenable to restoration ( $X=4.48, M=5, S=0.75, I Q R=1, P=92 \%$ )

- the molar is NOT considered to be a strategic tooth and is to be exposed to $\geq 50$ Gray $(X=4.40, M=4, S=0.69, I Q R=1, P=96 \%)$

- there is insufficient time for dismantling and assessment of the extent of the carious lesion prior to radiotherapy, and the molar is to be exposed to $\geq 50$ Gray $(X=4.12, M=4, S=0.82, I Q R=1, P=88 \%$ )

- the patient is considered to be dentally neglectful and the molar is to be exposed to $\geq 50$ Gray $(X=4.56, M=5, S=0.50, I Q R=1, P=100 \%)$

- there is NO parotid-gland sparing and the molar is to be exposed to $\geq 50$ Gray $(X=4.20, M=4, S=0.63, I Q R=1, P=88 \%$ )

- the patient is likely to develop severe trismus and the molar is to be exposed to $\geq 50$ Gray $(X=4.60, M=5, S=0.49, I Q R=1, P=100 \%$ )

- the molar has associated pathology as per 'mobile teeth', 'periodontal pocketing', 'furcation disease', 'tooth-restoration margin', 'root caries', 'other pathology' above $(X=4.40, M=5, S=0.70, I Q R=1, P=96 \%)$

2. Crowned molar teeth with secondary caries should be extracted prior to radiotherapy when:

- the molar is NOT amenable to restoration ( $X=4.38, M=4.5, S=0.75, I Q R=1, P=92 \%$ )

- the molar is NOT considered to be a strategic tooth and is to be exposed to $\geq 50$ Gray ( $X=4.04, M=4, S=0.89, I Q R=1, P=79 \%$ )

- there is insufficient time for dismantling and assessment of the extent of the carious lesion prior to radiotherapy, and the molar is to be exposed to $\geq 50$ 


\section{Gray $(X=4.08, M=4, S=0.69, I Q R=0, P=88 \%)$}

- the patient is considered to be dentally neglectful and the molar is to be exposed to $\geq 50$ Gray $(X=4.33, M=4, S=0.47, I Q R=1, P=100 \%$ )

- there is NO parotid-gland sparing and the molar is to be exposed to $\geq 50$ Gray ( $X=4.12, M=4, S=0.77, I Q R=1, P=84 \%$ )

- the patient is likely to develop severe trismus and the molar is to be exposed to $\geq 50$ Gray $(X=4.42, M=4, S=0.49, I Q R=1, P=100 \%)$

- the molar has associated pathology as per 'mobile teeth', 'periodontal pocketing', 'furcation disease', 'tooth-restoration margin', 'root caries', 'other pathology' above $(X=4.32, M=4, S=0.55, I Q R=1, P=96 \%)$

- the caries is suspected to be pulpally involved as above $(X=4.24, M=4, S=0.76$, $I Q R=1, P=88 \%$ )

3. Non-vital and/or root-treated molar teeth should be extracted prior to radiotherapy when:

- the molar is NOT amenable to restoration ( $X=4.28, M=4, S=0.66, I Q R=1, P=88 \%$ )

- the molar is NOT considered to be a strategic tooth, is to be exposed to $\geq 50$ Gray, and the performed root canal treatment (if completed) is deemed to be of poor quality ( $X=4.17, M=4, S=0.70, I Q R=1, P=92 \%$ )

- the molar is root-treated, has apical disease, and is to be exposed to $\geq 50$ Gray ( $X=4.36, M=4, S=0.56, I Q R=1, P=96 \%$ )

- the patient is considered to be dentally neglectful and the molar is to be exposed to $\geq 50$ Gray ( $X=4.20, M=4, S=0.57, I Q R=1, P=92 \%$ )

- there is NO parotid-gland sparing, the molar is to be exposed to $\geq 50$ Gray, and the performed root canal treatment (if completed) is deemed to be of poor quality ( $X=4.20, M=4, S=0.72, I Q R=1, P=92 \%)$

- the patient is likely to develop severe trismus and the molar is to be exposed to $\geq 50$ Gray $(X=4.42, M=4, S=0.57, I Q R=1, P=96 \%$ )

- the molar has associated pathology as per 'mobile teeth', 'periodontal pocketing', 'furcation disease', 'tooth-restoration margin', 'root caries', 'other pathology' above $(X=4.32, M=4, S=0.61, I Q R=1, P=92 \%)$

4. Molar teeth with evidence of apical disease should be extracted prior to radiotherapy when:

- the molar is NOT amenable to restoration ( $X=4.32, M=4, S=0.79, I Q R=1, P=88 \%$ )

- the molar is NOT considered to be a strategic tooth, and is to be exposed to $\geq 50$ Gray $(X=4.28, M=4, S=0.72, I Q R=1, P=84 \%)$

- the molar has already been root-treated and is to be exposed to $\geq 50$ Gray ( $X=$ 4.44, $M=4, S=0.58, I Q R=1, P=96 \%$ )

- the patient is considered to be dentally neglectful and the molar is to be exposed to $\geq 50$ Gray ( $X=4.44, M=4, S=0.50, I Q R=1, P=100 \%$ )

- there is NO parotid-gland sparing and the molar is to be exposed to $\geq 50$ Gray ( $X=4.17, M=4, S=0.80, I Q R=1, P=84 \%$ )

- the patient is likely to develop severe trismus and the molar is to be exposed to $\geq 50$ Gray ( $X=4.48, M=4, S=0.50, I Q R=1, P=100 \%$ )

- the molar has associated pathology as per 'mobile teeth', 'periodontal pocketing', 'furcation disease', 'tooth-restoration margin', 'root caries', 'other pathology' above $(X=4.38, M=4, S=0.56, I Q R=1, P=96 \%)$

\section{Premolar teeth}

1. Premolar teeth affected by caries or toothwear with suspected pulpal involvement 
should be extracted prior to radiotherapy when:

- the premolar is NOT amenable to restoration ( $X=4.24, M=4, S=0.81, I Q R=1, P=84 \%$ )

- there is insufficient time for dismantling and assessment of the extent of the carious lesion prior to radiotherapy, and the premolar is to be exposed to $\geq 50$ Gray ( $X=3.91, M=4, S=0.65, I Q R=0.5, P=74 \%$ )

- the patient is considered to be dentally neglectful and the premolar is to be exposed to $\geq 50$ Gray ( $X=4.32, M=4, S=0.55, I Q R=1, P=96 \%$ )

- the patient is likely to develop severe trismus and the premolar is to be exposed to $\geq 50$ Gray ( $X=4.00, M=4, S=0.75, I Q R=2, P=72 \%$ )

- the premolar has associated pathology as per 'mobile teeth', 'periodontal pocketing', 'furcation disease', 'tooth-restoration margin', 'root caries', 'other pathology' above $(X=4.12, M=4, S=0.65, I Q R=1, P=84 \%)$

2. Crowned premolar teeth with secondary caries should be extracted prior to radiotherapy when:

- the premolar is NOT amenable to restoration ( $X=4.12, M=4, S=0.82, I Q R=1, P=80 \%$ )

- there is insufficient time for dismantling and assessment of the extent of the carious lesion prior to radiotherapy, and the premolar is to be exposed to $\geq 50$ Gray ( $X=3.96, M=4, S=0.73, I Q R=0, P=79 \%)$

- the patient is considered to be dentally neglectful and the premolar is to be exposed to $\geq 50$ Gray ( $X=4.24, M=4, S=051$., $I Q R=1, P=96 \%$ )

- the patient is likely to develop severe trismus and the premolar is to be exposed to $\geq 50$ Gray ( $X=4.08, M=4, S=0.80, I Q R=1, P=80 \%$ )

- the premolar has associated pathology as per 'mobile teeth', 'periodontal pocketing', 'furcation disease', 'tooth-restoration margin', 'root caries', 'other pathology' above $(X=4.16, M=4, S=0.61, I Q R=1, P=88 \%)$

- the caries is suspected to be pulpally involved as above $(X=4.16, M=4, S=0.61$, $I Q R=1, P=88 \%)$

3. Non-vital and/or root-treated premolar teeth should be extracted prior to radiotherapy when:

- the premolar is NOT amenable to restoration ( $X=4.16, M=4, S=0.83, I Q R=1, P=80 \%)$

- the premolar has a post in-situ, has apical disease, and is to be exposed to $\geq 50$ Gray ( $X=4.16, M=4, S=0.67, I Q R=1, P=92 \%)$

- the patient is considered to be dentally neglectful and the premolar is to be exposed to $\geq 50$ Gray ( $X=4.04, M=4, S=0.77, I Q R=1, P=80 \%$ )

- the patient is likely to develop severe trismus and the premolar is to be exposed to $\geq 50$ Gray ( $X=3.96, M=4, S=0.92, I Q R=1, P=80 \%$ )

- the premolar has associated pathology as per 'mobile teeth', 'periodontal pocketing', 'furcation disease', 'tooth-restoration margin', 'root caries', 'other pathology' above $(X=4.12, M=4, S=0.49, I Q R=0, P=88 \%)$

4. Premolar teeth with evidence of apical disease should be extracted prior to radiotherapy when:

- the premolar is NOT amenable to restoration ( $X=4.28, M=4, S=0.66, I Q R=1, P=88 \%)$

- the premolar has a post in-situ and is to be exposed to $\geq 50$ Gray $(X=4.17, M=4$, $S=0.80, I Q R=1, P=84 \%$ )

- the patient is considered to be dentally neglectful and the premolar is to be exposed to $\geq 50$ Gray ( $X=4.24, M=4, S=0.51, I Q R=1, P=96 \%$ ) 
- the patient is likely to develop severe trismus and the premolar is to be exposed to $\geq 50$ Gray ( $X=4.12, M=4, S=0.77, I Q R=1, P=84 \%$ )

- the premolar has associated pathology as per 'mobile teeth', 'periodontal pocketing', 'furcation disease', 'tooth-restoration margin', 'root caries', 'other pathology' above $(X=4.08, M=4, S=0.74, I Q R=1, P=84 \%)$

\section{Anterior teeth}

1. Anterior teeth affected by caries or toothwear with suspected pulpal involvement should be extracted prior to radiotherapy when the tooth is NOT amenable to restoration $(X=4.00, M=4, S=0.96, I Q R=1, P=79 \%)$

2. Mandibular anterior teeth affected by caries or toothwear with suspected pulpal involvement should be extracted prior to radiotherapy when:

- there is insufficient time for dismantling and assessment of the extent of the carious lesion prior to radiotherapy, the tooth is NOT deemed to be of strategic importance, and the tooth is to be exposed to $\geq 50$ Gray $(X=4.00, M=4, S=0.42, I Q R=0$, $P=92 \%)$

- the tooth is NOT deemed to be of strategic importance, and has associated pathology as per 'mobile teeth', 'periodontal pocketing', 'furcation disease', 'tooth-restoration margin', 'root caries', 'other pathology' above $(X=3.77, M=4$, $S=0.87, I Q R=0, P=78 \%)$

3. Crowned anterior teeth with secondary caries should be extracted prior to radiotherapy when the tooth is NOT amenable to restoration $(X=4.12, M=4, S=0.91, I Q R=1$, $P=80 \%)$

4. Crowned mandibular anterior teeth with secondary caries should be extracted prior to radiotherapy when:

- there is insufficient time for dismantling and assessment of the extent of the carious lesion prior to radiotherapy, the tooth is NOT deemed to be of strategic importance, and the tooth is to be exposed to $\geq 50$ Gray $(X=4.13, M=4, S=0.68$, $I Q R=0.25, P=92 \%$ )

- the tooth is NOT deemed to be of strategic importance, and has associated pathology as per 'mobile teeth', 'periodontal pocketing', 'furcation disease', 'tooth-restoration margin', 'root caries', 'other pathology' above $(X=3.87, M=4$, $S=0.63, I Q R=0, P=83 \%)$

5. Non-vital and/or root-treated anterior teeth should be extracted prior to radiotherapy when:

- the tooth is NOT amenable to restoration ( $X=3.96, M=4, S=0.96, I Q R=1, P=76 \%$ )

- the tooth has a post in-situ, has apical disease, and is to be exposed to $\geq 50$ Gray $(X=3.88, M=4, S=1.03, I Q R=2, P=72 \%)$

6. Anterior teeth with evidence of apical disease should be extracted prior to radiotherapy when:

- the tooth is NOT amenable to restoration ( $X=4.20, M=4, S=0.75, I Q R=1, P=88 \%)$

- the tooth has a post in-situ and is to be exposed to $\geq 50$ Gray $(X=3.88, M=4, S=0.82$, $I Q R=0, P=84 \%$ )

7. Mandibular anterior teeth with evidence of apical disease should be extracted prior 
to radiotherapy when the tooth is NOT deemed to be of strategic importance, and has associated pathology as per 'mobile teeth', 'periodontal pocketing', 'furcation disease', 'tooth-restoration margin', 'root caries', 'other pathology' above $(X=3.68, M=4, S=0.65$, $I Q R=0, P=91 \%$ )

\section{Impacted and unerupted teeth}

1. Impacted and unerupted teeth should be extracted prior to radiotherapy when:

- they are carious and NOT amenable to restoration $(X=4.24, M=4, S=0.76, I Q R=1$, $P=88 \%)$

- $\quad$ they are associated with the tumour or in the field of resection $(X=4.44, M=5$, $S=0.90, I Q R=1, P=92 \%$ )

- other pathology is suspected (e.g. cyst formation, resorption of adjacent teeth) $(X=4.28, M=4, S=0.83, I Q R=1, P=96 \%)$

2. Partially erupted third molars (or other teeth) should be extracted prior to radiotherapy when the patient is considered to be dentally neglectful and the tooth is to be exposed to $\geq 50$ Gray $(X=4.33, M=4, S=0.70, I Q R=1, P=88 \%)$

\section{Roots}

1. Roots should only be retained prior to radiotherapy if they are encased entirely within bone, have NO associated pathology, are NOT within the field of tumour resection, and will NOT interfere with implant planning $(X=3.92, M=4, S=0.93, I Q R=0$, $P=88 \%)$

2. Healthy canine roots may be retained as overdenture abutments or for bone preservation in patients deemed NOT to be dentally neglectful $(X=4.04, M=4, S=0.46$, $I Q R=0, P=92 \%$ )

Table 3: Pool One consisting of statements that achieved consensus agreement among the expert panel. 


\section{Mobile teeth}

1. Teeth that are grade II or grade III mobile should be extracted prior to radiotherapy, excluding:

- restorable anterior teeth exposed to $<50$ Gray ( $X=3.00, M=3, S=1.04, I Q R=2, P=35 \%)$

- periodontally stable teeth (i.e. no periodontal pockets) exposed to $<50$ Gray ( $X=$ 3.15, $M=3, S=1.13, I Q R=2, P=47 \%$ )

- all of the above (insufficient responses)

2. Teeth that are grade II mobile, are periodontally stable (i.e. have no periodontal pockets), and are to be exposed to $\geq 50$ Gray may be retained prior to radiotherapy ( $X=$ 2.88, $M=3, S=1.08, I Q R=2, P=32 \%)$

3. Teeth that are grade II mobile, are deemed to be of strategic importance, and are to be exposed to $\geq 50$ Gray may be retained prior to radiotherapy ( $X=2.83, M=2.5, S=1.17$, $I Q R=2, P=33 \%$ )

\section{Periodontal pocketing}

Teeth that have a periodontal pocket of greater than $5 \mathrm{~mm}$ (i.e. $\geq 6 \mathrm{~mm}$ ) should be extracted prior to radiotherapy when:

- the tooth is grade II or III mobile ( $X=3.72, M=4, S=1.08, I Q R=2, P=56 \%)$

- the tooth is non-functional, is NOT considered to be a strategic tooth, and is to be exposed to $\geq 50$ Gray $(X=3.85, M=4, S=0.99, I Q R=2, P=66 \%$ )

- there are three or more pockets of greater than $5 \mathrm{~mm}$ on the same tooth and the tooth is to be exposed to $\geq 50$ Gray ( $X=3.84, M=4, S=0.88, I Q R=1, P=68 \%$ )

\section{Furcation disease}

Teeth with furcation disease should be extracted prior to radiotherapy when:

- the tooth has a grade II or III furcation defect and is to be exposed to $\geq 50$ Gray ( $X=4.00, M=4, S=0.96, I Q R=2, P=69 \%$ )

- the tooth has a periodontal pocket of greater than $5 \mathrm{~mm}$ (i.e. $\geq 6 \mathrm{~mm})(X=3.60$, $M=4, S=0.98, I Q R=1, P=60 \%)$

\section{Tooth-restoration margin}

Teeth with a sound tooth margin extending beyond $1 \mathrm{~mm}$ subgingivally should be extracted prior to radiotherapy when:

- the tooth is a premolar or molar and is to be exposed to $\geq 50$ Gray $(X=3.25, M=3$, $S=0.97, I Q R=2, P=46 \%)$

- $\quad$ the tooth is grade II or III mobile ( $X=3.80, M=4, S=0.94, I Q R=1, P=68 \%)$

- the tooth has a periodontal pocket of greater than $5 \mathrm{~mm}$ (i.e. $\geq 6 \mathrm{~mm})(X=3.56$, $M=4, S=0.90, I Q R=1, P=60 \%)$

\section{Root caries}

1. Teeth with root caries affecting two or more surfaces should be extracted prior to radiotherapy, excluding:

- restorable teeth exposed to $<50$ Gray $(X=3.58, M=4, S=0.79, I Q R=1, P=62 \%)$

- restorable teeth deemed to be of strategic importance $(X=3.77, M=4, S=0.70, I Q R=1$, $P=69 \%)$

- all of the above (insufficient responses)

2. Teeth with active root caries affecting two or more surfaces may be retained prior 
to radiotherapy when they are deemed to be restorable, there will be parotid gland sparing, and the tooth is to be exposed to $<50$ Gray ( $X=3.63, M=4, S=1.06, I Q R=1, P=67 \%$ )

3. Teeth with active root caries affecting two or more surfaces may be retained prior to radiotherapy when they are deemed to be restorable, there will be parotid gland sparing, and the tooth is to be exposed to $\geq 50$ Gray $(X=2.83, M=2.5, S=1.17, I Q R=2, P=33 \%)$

\section{Other pathology}

1. Teeth with root-perforations, root-resorption, root-fracture, or retained instruments should be extracted prior to radiotherapy, excluding:

- resorption lesions or perforations amenable to restoration in teeth exposed to $<50$ Gray $(X=3.08, M=3.5, S=1.00, I Q R=2, P=50 \%$ )

- long-standing asymptomatic teeth with retained instruments that have no apical pathology $(X=3.27, M=3.5, S=0.94, I Q R=1, P=50 \%)$

- $\quad$ all of the above (insufficient responses)

2. Long standing asymptomatic teeth with: (i) repaired perforations, or (ii) repaired/inactive resorption lesions, or (iii) root fracture, or (iv) retained instruments, and that have NO associated pathology, may be retained prior to radiotherapy ( $X=3.17, M=3, S=0.87, I Q R=2, P=46 \%$ )

\section{Unopposed molars}

1. Unopposed healthy molar teeth should ONLY be extracted prior to radiotherapy if they are exposed to $\geq 50$ Gray, are NOT deemed to be of strategic importance, and will NOT be opposed by a future prosthesis ( $X=2.96, M=2.5, S=1.13, I Q R=2, P=43 \%$ )

2. Unopposed healthy molar teeth should ONLY be extracted prior to radiotherapy if they are to be exposed to $\geq 50$ Gray, are NOT deemed to be of strategic importance, and will NOT be opposed by a future prosthesis, in a patient likely to develop severe trismus ( $X=3.54, M=4, S=0.93, I Q R=1, P=64 \%$ )

\section{Molar teeth}

Non-vital and/or root-treated molar teeth should be extracted prior to radiotherapy when:

- the molar is NOT considered to be a strategic tooth and is to be exposed to $\geq 50$ Gray ( $X=3.60, M=4, S=0.80, I Q R=1, P=56 \%$ )

- there is NO parotid-gland sparing and the molar is to be exposed to $\geq 50$ Gray ( $X=3.67, M=4, S=0.85, I Q R=1, P=59 \%$ )

\section{Premolar teeth}

1. Premolar teeth affected by caries or toothwear with suspected pulpal involvement should be extracted prior to radiotherapy when:

- the premolar is non-functional, is NOT considered to be a strategic tooth, and is to be exposed to $\geq 50$ Gray $(X=3.60, M=4, S=0.94, I Q R=1, P=60 \%)$

2. Crowned premolar teeth with secondary caries should be extracted prior to radiotherapy when:

- The premolar is non-functional, is NOT considered to be a strategic tooth, and is to be exposed to $\geq 50$ Gray $(X=3.60, M=4, S=0.89, I Q R=1, P=56 \%)$ 
3. Non-vital and/or root-treated premolar teeth should be extracted prior to radiotherapy when:

- the premolar is non-functional, is NOT considered to be a strategic tooth, and is to be exposed to $\geq 50$ Gray $(X=3.48, M=3, S=0.98, I Q R=1, P=44 \%$ )

4. Premolar teeth with evidence of apical disease should be extracted prior to radiotherapy when:

- the premolar is non-functional, is NOT considered to be a strategic tooth, and is to be exposed to $\geq 50$ Gray $(X=3.79, M=4, S=0.96, I Q R=1.25, P=67 \%)$

\section{Anterior teeth}

1. Anterior teeth affected by caries or toothwear with suspected pulpal involvement should be extracted prior to radiotherapy when:

- there is insufficient time for dismantling and assessment of the extent of the carious lesion prior to radiotherapy, and the tooth is to be exposed to $\geq 50$ Gray $(X=3.44, M=4, S=1.10, I Q R=2, P=52 \%)$

- the tooth has associated pathology as per 'mobile teeth', 'periodontal pocketing', 'furcation disease', 'tooth-restoration margin', 'root caries', 'other pathology' above $(X=3.52, M=4, S=0.98, I Q R=1, P=64 \%)$

2. Crowned anterior teeth with secondary caries should be extracted prior to radiotherapy when:

- there is insufficient time for dismantling and assessment of the extent of the carious lesion prior to radiotherapy, and the tooth is to be exposed to $\geq 50$ Gray $(X=3.44, M=3, S=1.06, I Q R=1, P=48 \%)$

- the tooth has associated pathology as per 'mobile teeth', 'periodontal pocketing', 'furcation disease', 'tooth-restoration margin', 'root caries', 'other pathology' above ( $X=3.56, M=4, S=.0 .94, I Q R=1, P=64 \%$ )

- the caries is pulpally involved ( $X=3.33, M=3, S=1.03, I Q R=1.25, P=42 \%)$

3. Non-vital and/or root-treated anterior teeth should be extracted prior to radiotherapy when:

- the tooth has associated pathology as per 'mobile teeth', 'periodontal pocketing', 'furcation disease', 'tooth-restoration margin', 'root caries', 'other pathology' above $(X=3.68, M=4, S=0.93, I Q R=1, P=68 \%)$

4. Anterior teeth with evidence of apical disease should be extracted prior to radiotherapy when:

- the tooth has associated pathology as per 'mobile teeth', 'periodontal pocketing', 'furcation disease', 'tooth-restoration margin', 'root caries', 'other pathology' above $(X=3.64, M=4, S=0.89, I Q R=1, P=68 \%)$

5. Crowned mandibular anterior teeth with secondary caries should be extracted prior to radiotherapy when the tooth is NOT deemed to be of strategic importance, and the caries is expected to be pulpally involved $(X=3.87, M=4, S=0.69, I Q R=1, P=69 \%$ )

6. Non-vital and/or root-treated mandibular anterior teeth should be extracted prior to radiotherapy when the tooth is NOT deemed to be of strategic importance, and has 
associated pathology as per 'mobile teeth', 'periodontal pocketing', 'furcation disease', 'tooth-restoration margin', 'root caries', 'other pathology' above $(X=3.61, M=4, S=0.66$, $I Q R=1, P=69 \%)$

\section{Impacted and unerupted teeth}

Impacted and unerupted teeth should be extracted prior to radiotherapy when:

- the patient is considered to be dentally neglectful and the tooth is to be exposed to $\geq 50$ Gray ( $X=3.42, M=3, S=1.15, I Q R=2.25, P=46 \%$ )

- $\quad$ if the adjacent erupted tooth is to be extracted and it is likely to change position $(X=3.28, M=3, S=0.83, I Q R=1, P=36 \%$ )

Table 4: Pool Two consisting of statements that did not achieve consensus agreement among the expert panel.

\section{Discussion}

A total of 89 consensus statements represent the consensus professional views of participated consultants in restorative dentistry in the United Kingdom and Ireland regarding the types of teeth that should be extracted prior to radiotherapy in HNC patients. The consensus statements pertain to the decision-making process for the preradiotherapy extraction of molar, premolar, and anterior teeth with periodontal pocketing, furcation disease, mobility, dental caries, tooth-wear, apical disease, and other associated pathology. A further eight statements did not achieve consensus agreement after Round 3, and the clinician researchers felt that there were an inadequate number of comments provided to facilitate their further modification and re-inclusion in a fourth Delphi-round.

The Delphi technique was employed to meet the objectives of this study for the following reasons: (i) a current paucity of published research and guidance concerning pre-radiotherapy dental extractions in HNC patients;[46,47] (ii) ethical issues associated with the randomisation of pre-radiotherapy dental extractions in cancer patients; and (iii) previous evidence that has demonstrated disparities in clinical decision-making regarding pre-radiotherapy extractions in HNC patients[48,49].

In a survey of 65 restorative dentistry consultants, specialist registrars, specialist practitioners, and trust grade dentists, Dewan et al. found substantial variability in the clinical approach to the dental and oral rehabilitation of a 74-year old man with a heavily restored dentition diagnosed with a malignant melanoma of the right cheek. [49] The results indicated that all respondents (100\%) agreed with the plan to extract decayed retained roots, however, less than 30\% agreed with the proposed preradiotherapy extraction of non-carious premolar teeth, and less than $60 \%$ agreed with the proposed extraction of heavily restored non-carious molars.[49]

Furthermore, a survey by Bruins et al. also found heterogeneity in the clinical approach of 44 oral-maxillofacial surgeons and hospital-based dentists in relation to the preradiotherapy extraction of teeth with moderate dental pathosis (e.g. teeth with periodontal pockets of 3-5 $\mathrm{mm}$ or teeth with bleeding on probing); teeth with condensing osteitis; and fully impacted mandibular third molar teeth.[48] Moreover, the results of this study's literature review also highlight international disparities in the clinical approach to pre-radiotherapy dental extractions for HNC patients. 
The study presented here invited all members of the BSSPD, and all restorative dentistry consultants working in the Republic of Ireland, to participate. A good response rate was achieved with minimal attrition - a higher than $70 \%$ response rate was achieved for each of the three, iterative rounds.[35] In Round 1, 10 out of the 38 (26\%) respondents who had initially agreed to take part failed to complete the questionnaire and were withdrawn from the study. During Rounds 2 and 3, a further 2 out of 28 (7\%), and 2 out of 26 (8\%) participants, failed to return their questionnaires respectively. There was limited data regarding respondents and non-respondents, however, there did not appear to be any systematic bias when they were compared.

Definitions of group consensus differ substantially between Delphi studies, however, cut-offs based on a percentage level of agreement (e.g. greater than or equal to $70 \%$ agreement), or median scores (e.g. 4 or 5 on a 5 -point Likert scale), or a combination of both, have been most commonly used.[35,36,38,50,51] The interquartile range (IQR less than or equal to 2) has also been considered an objective and rigorous method for determining group consensus.[52] In addition to attaining greater than or equal to $70 \%$ agreement, all 89 consensus statements had a median score of 4 or 5 , and an IQR of less than or equal to 2. IQRs of less than or equal to 1 , indicating "strong consensus agreement" according to van der Maaden et al.,[53] were also calculated for 85 (96\%) of these statements.

A total of 41 statements did not attain consensus agreement. For 18 (44\%) of these statements, a percentage level of agreement of between 60 and $70 \%$ was achieved. For $5(12 \%)$ statements, a percentage level of agreement of less than $30 \%$ was attained. Statements that did not achieve consensus agreement represent substantial heterogeneity in consultant opinion regarding the pre-radiotherapy management of unopposed molar teeth; teeth with root caries; upper anterior teeth with different pathologies; and long-standing, non-pathological, asymptomatic teeth with repaired perforations, repaired resorption, root fractures, or retained instruments.

\section{Strengths and limitations}

This study adhered to best research practice in terms of being guided by the commonly reported features of Delphi studies.[36] Whilst it may be argued that the Delphi technique may be vulnerable to bias, $[35,36]$ if it is used properly, and is conducted and reported on in line with current best available recommendations, it can facilitate the determination of justifiable, valid, and credible conclusions based on up-to-date evidence and the collective 'expert' opinion of its participants.[36]

Biases associated with the Delphi process may include: the invitation of panel members; participants' previous clinical experience or recall availability; participants' aim to please or avoid embarrassment; and information-sharing between rounds.[35,54] In this study, the research team attempted to recruit as many UK consultants in restorative dentistry as possible, and enhance the study's overall appeal, by approaching the British Society of Prosthodontics (BSSPD). At the start of 2020, there were 72 active members of the BSSPD who identified as 'restorative dentistry specialists', however, not all of these members would have been eligible for participation based on the study's exclusion criteria.[55] 
During the conduct of a Delphi study, the anonymity afforded to participants is considered to be advantageous in comparison to other group consensus methods, as it may prevent information-sharing, and reduce biases associated with intimidation and geographical proximity of participants.[35] In addition, the research team also attempted to minimise bias associated with the study's literature review, by completing a systematic scope of the literature, using researchers who had previous experience of conducting systematic reviews.[13,56]

As part of the Delphi process, it must be remembered that consensus 'expert' agreement does not always imply that the 'correct' answer or judgement has been obtained.[36] A participant in this study withdrew their participation after Round 2 over their concerns that the results could be "potentially dangerous", in the sense that the study's outputs could be interpreted as "binding clinical guidelines". It is important to reiterate, however, that the 89 consensus statements attained represent the consensus professional views of participated consultants in restorative dentistry in the United Kingdom and Ireland regarding the types of teeth that should be extracted before radiotherapy in HNC patients. It is envisaged that the results of this study will be used to help to inform the development of future clinical guidelines in another setting, for example, at a national or international conference.

\section{Clinical implications}

Pre-radiotherapy dental extractions aim to avoid the need for post-radiotherapy extractions and the associated risk of ORN, as well as, prevent dental issues that could lead to the interruption of oncology treatment.[30] Research evidence regarding the effectiveness of pre-radiotherapy extractions in HNC patients, however, remains inconclusive, and more research is needed in this area.[47] Knowledge of a patient's oncology prognosis is essential for the development of an appropriate, individually tailored, pre-radiotherapy dental treatment plan. The list of factors that may influence patients' survival from HNC, as presented in this study's literature review and incorporated into the Delphi-tested statements, needs to be tempered with a close working relationship with the clinical oncology team, as well as, the maxillofacial and ENT surgical teams. Adequate restorative dentistry representation at the multidisciplinary team meeting for HNC patients should also be mandatory. Preradiotherapy extractions are associated with an approximate 4\% risk of ORN.[57] Dental extractions should therefore be undertaken sufficiently early in the patient's care pathway to facilitate satisfactory healing of the bone socket prior to oncology treatment. Many argue that this timeframe should be at least 10 days, $[30,57]$ however, there are cases in the literature of ORN having developed at tooth-extraction sites left to heal for longer than 21 days[57-59]. Close follow-up of patients who have recently had preradiotherapy dental extractions is therefore essential.

Anecdotally, in the UK and Ireland, clinical specialists in oral surgery, special care dentistry, and restorative dentistry mono-specialties such as prosthodontics, periodontics, and endodontics, have also been involved in the treatment planning of pre-radiotherapy HNC patients. However, official guidance endorsed by the UK specialty associations involved in the care of HNC patients, and the Royal College of Surgeons of England, recommend that the dental management of these patients should be led by a consultant in restorative dentistry.[5,30] Currently, trainee-consultants in restorative dentistry in the UK and Ireland must undergo specific training in the oral and dental 
treatment planning of HNC patients, in line with the Curriculum for Specialty Training in Restorative Dentistry.[60]

\section{Conclusion}

The results of this Delphi study represent the consensus professional views of participated consultants in restorative dentistry in the UK and Ireland regarding the types of teeth that should be extracted prior to radiotherapy in patients with head and neck cancer. A total of 89 consensus statements are presented concerning the preradiotherapy dental extraction of molar, premolar, or anterior teeth with periodontal pocketing, furcation disease, mobility, dental caries, tooth-wear, apical disease, and other associated pathology. It is hoped that the results of this study will help to inform the development of future clinical guidelines regarding the pre-radiotherapy extraction of teeth for head and neck cancer patients.

\section{$\underline{\text { References }}$}

[1] A. Jemal, F. Bray, M.M. Center, J. Ferlay, E. Ward, D. Forman, Global cancer statistics, CA. Cancer J. Clin. 61 (2011) 69-90. https://doi.org/10.3322/caac.20107.

[2] Cancer Research UK, Head and neck cancers statistics | Cancer Research UK, (2019). https://www.cancerresearchuk.org/health-professional/cancerstatistics/statistics-by-cancer-type/head-and-neck-cancers (accessed February 22, 2019).

[3] Office for National Statistics, Survival estimates for head and neck cancers - Office for National Statistics, (2018).

[4] National Cancer Registration and Analysis Service, Chemotherapy, Radiotherapy and Surgical Tumour Resections in England: 2013-2015 diagnoses, (2018). http://www.ncin.org.uk/cancer_type_and_topic_specific_work/topic_specific_wor k/main_cancer_treatments (accessed February 22, 2019).

[5] V. Paleri, N. Roland, Introduction to the United Kingdom National Multidisciplinary Guidelines for Head and Neck Cancer, J. Laryngol. Otol. 130 (2016) S3-S4. https://doi.org/10.1017/S0022215116000359.

[6] K. Harrington, C. Nutting, K. Newbold, S. Bhide, Principles and Practice of Head and Neck Surgery and Oncology, 2nd ed., Chapman and Hall/CRC, 2009.

[7] M.U.R. Naidu, G.V. Ramana, P.U. Rani, lyyapu K. Mohan, A. Suman, P. Roy, Chemotherapy-Induced and/or Radiation Therapy-Induced Oral MucositisComplicating the Treatment of Cancer, Neoplasia. 6 (2004) 423-431. https://doi.org/10.1593/neo.04169.

[8] R.-J. Bensadoun, D. Riesenbeck, P.B. Lockhart, L.S. Elting, F.K.L. Spijkervet, M.T. Brennan, M.A. for S.C. in C. (MASCC)/International S. of 0.O. (ISO0) Trismus Section, Oral Care Study Group, A systematic review of trismus induced by cancer therapies in head and neck cancer patients, Support. Care Cancer. 18 (2010) 1033-1038. https://doi.org/10.1007/s00520-010-0847-4.

[9] S.B. Jensen, A.M.L. Pedersen, A. Vissink, E. Andersen, C.G. Brown, A.N. Davies, J. Dutilh, J.S. Fulton, L. Jankovic, N.N.F. Lopes, A.L.S. Mello, L. V. Muniz, C.A. MurdochKinch, R.G. Nair, J.J. Napeñas, A. Nogueira-Rodrigues, D. Saunders, B. Stirling, I. von Bültzingslöwen, D.S. Weikel, L.S. Elting, F.K.L. Spijkervet, M.T. Brennan, M.A. of S.C. in C. (MASCC)/International S. of 0.0. (ISO0) Salivary Gland

Hypofunction/Xerostomia Section, Oral Care Study Group, A systematic review of 
salivary gland hypofunction and xerostomia induced by cancer therapies: prevalence, severity and impact on quality of life, Support. Care Cancer. 18 (2010) 1039-1060. https://doi.org/10.1007/s00520-010-0827-8.

[10] C.H.L. Hong, S. Hu, T. Haverman, M. Stokman, J.J. Napeñas, J.B. Braber, E. Gerber, M. Geuke, E. Vardas, T. Waltimo, S.B. Jensen, D.P. Saunders, A systematic review of dental disease management in cancer patients, Support. Care Cancer. 26 (2018) 155-174. https://doi.org/10.1007/s00520-017-3829-y.

[11] J.B. Epstein, P. Stevenson-Moore, Periodontal disease and periodontal management in patients with cancer., Oral Oncol. 37 (2001) 613-9.

[12] S. Nabil, N. Samman, Incidence and prevention of osteoradionecrosis after dental extraction in irradiated patients: a systematic review, Int. J. Oral Maxillofac. Surg. 40 (2011) 229-243. https://doi.org/10.1016/j.ijom.2010.10.005.

[13] C. Moore, C. McLister, C. Cardwell, C. O’Neill, M. Donnelly, G. McKenna, Dental caries following radiotherapy for head and neck cancer: A systematic review, Oral Oncol. 100 (2020) 104484. https://doi.org/10.1016/j.oraloncology.2019.104484.

[14] V.M. Duarte, Y.F. Liu, S. Rafizadeh, T. Tajima, V. Nabili, M.B. Wang, Comparison of Dental Health of Patients with Head and Neck Cancer Receiving IMRT vs Conventional Radiation, Otolaryngol. Neck Surg. 150 (2014) 81-86. https://doi.org/10.1177/0194599813509586.

[15] J.M. Schuurhuis, M.A. Stokman, J.L.N. Roodenburg, H. Reintsema, J.A. Langendijk, A. Vissink, F.K.L. Spijkervet, Efficacy of routine pre-radiation dental screening and dental follow-up in head and neck oncology patients on intermediate and late radiation effects. A retrospective evaluation, Radiother. Oncol. 101 (2011) 403409. https://doi.org/10.1016/j.radonc.2011.09.018.

[16] A.T. Monroe, D. Flesher-Bratt, C.G. Morris, A. V. Peddada, Prospectively-collected, tooth-specific dosimetry correlated with adverse dental outcomes, Oral Surg. Oral Med. Oral Pathol. Oral Radiol. 122 (2016) 158-163. https://doi.org/10.1016/j.oooo.2016.03.005.

[17] A.C. Bueno, R.C. Ferreira, F.I. Barbosa, B.C. Jham, C.S. Magalhães, A.N. Moreira, Periodontal care in patients undergoing radiotherapy for head and neck cancer, Support. Care Cancer. 21 (2013) 969-975. https://doi.org/10.1007/s00520-0121614-5.

[18] J. Escoda-Francoli, A. Rodriguez-Rodriguez, S. Perez-Garcia, J. Gargallo-Albiol, C. Gay-Escoda, Dental implications in oral cancer patients, Med. Oral Patol. Oral y Cir. Bucal. (2011) e508-e513. https://doi.org/10.4317/medoral.16.e508.

[19] S. Sennhenn-Kirchner, F. Freund, S. Grundmann, A. Martin, M. Borg-von Zepelin, H. Christiansen, H.A. Wolff, H.-G. Jacobs, Dental therapy before and after radiotherapy--an evaluation on patients with head and neck malignancies, Clin. Oral Investig. 13 (2009) 157-164. https://doi.org/10.1007/s00784-008-0229-1.

[20] A. Vissink, J. Jansma, F.K.L. Spijkervet, F.R. Burlage, R.P. Coppes, Oral sequelae of head and neck radiotherapy., Crit. Rev. Oral Biol. Med. 14 (2003) 199-212.

[21] H.F.J. Lieshout, C.P. Bots, The effect of radiotherapy on dental hard tissue-a systematic review, Clin. Oral Investig. 18 (2014) 17-24. https://doi.org/10.1007/s00784-013-1034-z.

[22] A.M. Kielbassa, W. Hinkelbein, E. Hellwig, H. Meyer-Lückel, Radiation-related damage to dentition, Lancet Oncol. 7 (2006) 326-335. https://doi.org/10.1016/S1470-2045(06)70658-1.

[23] J.B. Epstein, R. Lunn, N. Le, P. Stevenson-Moore, Periodontal attachment loss in patients after head and neck radiation therapy, Oral Surg. Oral Med. Oral Pathol. 
Oral Radiol. Endod. 86 (1998) 673-677. https://doi.org/10.1016/S10792104(98)90202-5.

[24] W.E. Wright, Periodontium Destruction Associated with Oncology Therapy, J. Periodontol. 58 (1987) 559-563. https://doi.org/10.1902/jop.1987.58.8.559.

[25] F. Sulaiman, J.M. Huryn, I.M. Zlotolow, Dental extractions in the irradiated head and neck patient: a retrospective analysis of Memorial Sloan-Kettering Cancer Center protocols, criteria, and end results., J. Oral Maxillofac. Surg. 61 (2003) 1123-31.

[26] R.E. Marx, Osteoradionecrosis: a new concept of its pathophysiology., J. Oral Maxillofac. Surg. 41 (1983) 283-8.

[27] G. Widmark, S. Sagne, P. Heikel, Osteoradionecrosis of the jaws, Int. J. Oral Maxillofac. Surg. 18 (1989) 302-306. https://doi.org/10.1016/S09015027(89)80100-6.

[28] J.A. Rivero, O. Shamji, A. Kolokythas, Osteoradionecrosis: a review of pathophysiology, prevention and pharmacologic management using pentoxifylline, $\alpha$-tocopherol, and clodronate, Oral Surg. Oral Med. Oral Pathol. Oral Radiol. 124 (2017) 464-471. https://doi.org/10.1016/j.oooo.2017.08.004.

[29] S.N. Rogers, J.J. D’Souza, D. Lowe, A. Kanatas, Longitudinal evaluation of healthrelated quality of life after osteoradionecrosis of the mandible, Br. J. Oral Maxillofac. Surg. 53 (2015) 854-857. https://doi.org/10.1016/j.bjoms.2015.07.008.

[30] N. Kumar, The Oral Management of Oncology Patients Requiring Radiotherapy, Chemotherapy and / or Bone Marrow Transplantation - Clinical Guidelines, R. Coll. Surg. Engl. / Br. Soc. Disabil. Oral Heal. (2019). https://www.rcseng.ac.uk//media/files/rcs/fds/publications/rcs-oncology-guideline-update--v3515119.pdf (accessed February 22, 2019).

[31] G. Studer, C. Glanzmann, S.P. Studer, K.W. Grätz, M. Bredell, M. Locher, U.M. Lütolf, R.A. Zwahlen, Risk-adapted dental care prior to intensity-modulated radiotherapy (IMRT)., Schweizer Monatsschrift Fur Zahnmedizin = Rev. Mens. Suisse d'odontoStomatologie = Riv. Mens. Svizz. Di Odontol. e Stomatol. 121 (2011) 216-29.

[32] C. Hentz, A.Z. Diaz, R.W. Borrowdale, B. Emami, M. Kase, M. Choi, Establishing a targeted plan for prophylactic dental extractions in patients with laryngeal cancer receiving adjuvant radiotherapy, Oral Surg. Oral Med. Oral Pathol. Oral Radiol. 122 (2016) 43-49. https://doi.org/10.1016/j.oooo.2016.01.021.

[33] M.A. Ben-David, M. Diamante, J.D. Radawski, K.A. Vineberg, C. Stroup, C.-A. Murdoch-Kinch, S.R. Zwetchkenbaum, A. Eisbruch, Lack of osteoradionecrosis of the mandible after intensity-modulated radiotherapy for head and neck cancer: likely contributions of both dental care and improved dose distributions, Int. J. Radiat. Oncol. Biol. Phys. 68 (2007) 396-402. https://doi.org/10.1016/j.ijrobp.2006.11.059.

[34] M.J. Wahl, Osteoradionecrosis prevention myths, Int. J. Radiat. Oncol. 64 (2006) 661-669. https://doi.org/10.1016/j.ijrobp.2005.10.021.

[35] C.K. Cramer, G.D. Klasser, J.B. Epstein, S.B. Sheps, The Delphi Process in Dental Research, J. Evid. Based Dent. Pract. 8 (2008) 211-220. https://doi.org/10.1016/j.jebdp.2008.09.002.

[36] S. Jünger, S.A. Payne, J. Brine, L. Radbruch, S.G. Brearley, Guidance on Conducting and REporting DElphi Studies (CREDES) in palliative care: Recommendations based on a methodological systematic review, Palliat. Med. 31 (2017) 684-706. https://doi.org/10.1177/0269216317690685. 
[37] S. Keeney, F. Hasson, H. McKenna, The Delphi Technique in Nursing and Health Research, Wiley-Blackwell, Oxford, UK, 2011. https://doi.org/10.1002/9781444392029.

[38] L. Li, D.E. Morse, R. V. Katz, What constitutes a proper routine oral cancer examination for patients at low risk? Findings from a Delphi survey, Oral Surg. Oral Med. Oral Pathol. Oral Radiol. 116 (2013) e379-e386. https://doi.org/10.1016/j.oooo.2013.07.010.

[39] E.A. Holey, J.L. Feeley, J. Dixon, V.J. Whittaker, An exploration of the use of simple statistics to measure consensus and stability in Delphi studies, BMC Med. Res. Methodol. 7 (2007) 52. https://doi.org/10.1186/1471-2288-7-52.

[40] S.C. Slade, C.E. Dionne, M. Underwood, R. Buchbinder, B. Beck, K. Bennell, L. Brosseau, L. Costa, F. Cramp, E. Cup, L. Feehan, M. Ferreira, S. Forbes, P. Glasziou, B. Habets, S. Harris, J. Hay-Smith, S. Hillier, R. Hinman, A. Holland, M. Hondras, G. Kelly, P. Kent, G.-J. Lauret, A. Long, C. Maher, L. Morso, N. Osteras, T. Peterson, R. Quinlivan, K. Rees, J.-P. Regnaux, M. Rietberg, D. Saunders, N. Skoetz, K. Sogaard, T. Takken, M. van Tulder, N. Voet, L. Ward, C. White, Consensus on Exercise Reporting Template (CERT): Modified Delphi Study, Phys. Ther. 96 (2016) 15141524. https://doi.org/10.2522/ptj.20150668.

[41] M.B. Miles, A.M. Huberman, J. Saldaña, Qualitative data analysis : a methods sourcebook, 4th ed., SAGE Publications, Inc, 2019.

[42] M.M. Curi, L.L. Dib, Osteoradionecrosis of the jaws: a retrospective study of the background factors and treatment in 104 cases., J. Oral Maxillofac. Surg. 55 (1997) 540-4; discussion 545-6. https://doi.org/10.1016/s02782391(97)90478-x.

[43] A.A. Owosho, C.J. Tsai, R.S. Lee, H. Freymiller, A. Kadempour, S. Varthis, A.Z. Sax, E.B. Rosen, S.K. Yom, J. Randazzo, E. Drill, E. Riedel, S. Patel, N.Y. Lee, J.M. Huryn, C.L. Estilo, The prevalence and risk factors associated with osteoradionecrosis of the jaw in oral and oropharyngeal cancer patients treated with intensitymodulated radiation therapy (IMRT): The Memorial Sloan Kettering Cancer Center experience, Oral Oncol. 64 (2017) 44-51. https://doi.org/10.1016/j.oraloncology.2016.11.015.

[44] C.J. Tsai, T.M. Hofstede, E.M. Sturgis, A.S. Garden, M.E. Lindberg, Q. Wei, S.L. Tucker, L. Dong, Osteoradionecrosis and Radiation Dose to the Mandible in Patients With Oropharyngeal Cancer, Int. J. Radiat. Oncol. Biol. Phys. 85 (2013) 415-420. https://doi.org/10.1016/j.ijrobp.2012.05.032.

[45] J.O. Deasy, V. Moiseenko, L. Marks, K.S.C. Chao, J. Nam, A. Eisbruch, Radiotherapy Dose-Volume Effects on Salivary Gland Function, Int. J. Radiat. Oncol. 76 (2010) S58-S63. https://doi.org/10.1016/j.ijrobp.2009.06.090.

[46] S. Eliyas, A. Al-Khayatt, R.W. Porter, P. Briggs, Dental extractions prior to radiotherapy to the jaws for reducing post-radiotherapy dental complications, Cochrane Database Syst. Rev. (2013) CD008857. https://doi.org/10.1002/14651858.CD008857.pub2.

[47] J.M. Schuurhuis, M.A. Stokman, M.J.H. Witjes, P.U. Dijkstra, A. Vissink, F.K.L. Spijkervet, Evidence supporting pre-radiation elimination of oral foci of infection in head and neck cancer patients to prevent oral sequelae. A systematic review, Oral Oncol. 51 (2015) 212-220. https://doi.org/10.1016/j.oraloncology.2014.11.017.

[48] H.H. Bruins, D.E. Jolly, R. Koole, Preradiation dental extraction decisions in patients with head and neck cancer., Oral Surg. Oral Med. Oral Pathol. Oral Radiol. 
Endod. 88 (1999) 406-12.

[49] K. Dewan, R.D. Kelly, P. Bardsley, A national survey of consultants, specialists and specialist registrars in restorative dentistry for the assessment and treatment planning of oral cancer patients, Br. Dent. J. 216 (2014) E27-E27. https://doi.org/10.1038/sj.bdj.2014.544.

[50] D.A. Mahler, P.A. Selecky, C.G. Harrod, J.O. Benditt, V. Carrieri-Kohlman, J.R. Curtis, H.L. Manning, R.A. Mularski, B. Varkey, M. Campbell, E.R. Carter, J.R. Chiong, E.W. Ely, J. Hansen-Flaschen, D.E. O’Donnell, A. Waller, American College of Chest Physicians Consensus Statement on the Management of Dyspnea in Patients With Advanced Lung or Heart Disease, Chest. 137 (2010) 674-691. https://doi.org/10.1378/chest.09-1543.

[51] D.A. Mahler, P.A. Selecky, C.G. Harrod, Management of dyspnea in patients with advanced lung or heart disease: practical guidance from the American college of chest physicians consensus statement., Pol. Arch. Med. Wewn. 120 (2010) 160-6.

[52] H.A. von der Gracht, Consensus measurement in Delphi studies: Review and implications for future quality assurance, Technol. Forecast. Soc. Change. 79 (2012) 1525-1536. https://doi.org/10.1016/J.TECHFORE.2012.04.013.

[53] T. van der Maaden, J.T. van der Steen, H.C.W. de Vet, W.P. Achterberg, F. Boersma, J.M.G.A. Schols, J.F.J.M. van Berkel, D.R. Mehr, M. Arcand, A.I.M. Hoepelman, R.T.C.M. Koopmans, C.M.P.M. Hertogh, Development of a practice guideline for optimal symptom relief for patients with pneumonia and dementia in nursing homes using a Delphi study, Int. J. Geriatr. Psychiatry. 30 (2015) 487-496. https://doi.org/10.1002/gps.4167.

[54] C. Christensen, J.R. Larson, Collaborative Medical Decision Making, Med. Decis. Mak. 13 (1993) 339-346. https://doi.org/10.1177/0272989X9301300410.

[55] The British Society of Prosthodontics (BSSPD), BSSPD: Find a member, (2020). https://www.bsspd.org/Members+only/Find+a+member.aspx (accessed April 17, 2020).

[56] C. McLister, M. Donnelly, C.R. Cardwell, C. Moore, C. O’Neill, P. Brocklehurst, G. McKenna, Effectiveness of prosthodontic interventions and survival of remaining teeth in adult patients with shortened dental arches-A systematic review, J. Dent. 78 (2018). https://doi.org/10.1016/j.jdent.2018.02.003.

[57] Y. Jiang, X. Zhu, S. Qu, Incidence of osteoradionecrosis in patients who have undergone dental extraction prior to radiotherapy: A systematic review and meta-analysis, J. Oral Maxillofac. Surgery, Med. Pathol. 26 (2014) 269-275. https://doi.org/10.1016/J.AJOMS.2014.03.010.

[58] J.B. Epstein, G. Rea, F.L.W. Wong, J. Spinelli, P. Stevenson- Moore, Osteonecrosis: Study of the relationship of dental extractions in patients receiving radiotherapy, Head Neck Surg. 10 (1987) 48-54. https://doi.org/10.1002/hed.2890100108.

[59] J.W. Schweiger, Oral complications following radiation therapy: A five-year retrospective report, J. Prosthet. Dent. 58 (1987) 78-82. https://doi.org/10.1016/S0022-3913(87)80148-8.

[60] General Dental Council (GDC), General Dental Council - Specialist lists, (2020). https://www.gdc-uk.org/registration/your-registration/specialist-lists. 